\title{
A AGLOMERAÇÃO DE XANGAI E AS TRANSFORMAÇÕES DA ESTRUTURA ESPACIAL DA SUA ÁREA CENTRAL: DECLÍNIO E RENOVAÇÃO
}

\author{
Lucimara Flávio Reis \\ Universidade Federal da Integração Latino-Americana, curso de Ciência Política e Sociologia, \\ Foz de Iguaçu, Paraná, Brasil.
}

\begin{abstract}
Resumo
O objetivo deste artigo é examinar a estrutura espacial da cidade de Xangai, localizada na República Popular da China, com enfoque na evolução do conjunto de substituição dos usos do solo no centro da aglomeração, como resultado da gradual abertura econômica. A cidade será enquadrada e serão apontados alguns processos por meio dos quais se deu o seu formidável desenvolvimento. Como se verá, a mudança na economia política ocasionada pela introdução de mecanismos de mercado apresentou três efeitos principais diretos sobre o tecido urbano: a descentralização, a expansão e a remodelação ou readaptação de estruturas urbanas. Com base nessa contextualização, serão apresentados argumentos que corroboram a tese de que a entrada em novo patamar econômico, possibilitada por decisões de planejamento que resultaram nas reformas econômicas, trouxe mudanças significativas para a economia política do desenvolvimento urbano, ao determinar o processo de substituição dos usos do solo, com a recuperação radical de estruturas existentes para novos usos do capital.

Palavras-chave Xangai; usos do solo; planejamento; desenvolvimento urbano; estrutura urbana.
\end{abstract}


SHANGHAI URBAN AGGLOMERATION AND THE SPATIAL STRUCTURE TRANSFORMATIONS OF ITS CENTRAL AREA: DECLINE AND RENOVATION

\author{
Lucimara Flávio Reis \\ Universidade Federal da Integração Latino-Americana, curso de Ciência Política e Sociologia, \\ Foz de Iguaçu, Paraná, Brasil.
}

\begin{abstract}
The aim of this paper is to examine the spatial structure of the city of Shanghai, located in the People's Republic of China, highlighting the evolution of the land use change in the center of the agglomeration, starting from the economic reforms. We will see that the change in political economy, brought about by the introduction of market mechanisms, had three main effects both direct and reciprocal on the urban fabric: decentralization, expansion and remodeling the urban structures. By doing so, we will try to elaborate arguments that support the idea that its new economic level, made possible by planning decisions and resulted in the economic reforms of the late 1980s, brought significant changes to the political economy of urban development. As a result, the changes have determined the process of accelerated substitution of land uses, with the radical recovering of existing structures for new uses of capital.

Key-words

Shanghai; land use; planning; urban development; urban structure.
\end{abstract}




\title{
A AGLOMERAÇÃO DE XANGAI E AS TRANSFORMAÇÕES DA ESTRUTURA ESPACIAL DA SUA ÁREA CENTRAL: DECLÍNIO E RENOVAÇÃO'
}

\author{
Lucimara Flávio Reis
}

\section{Introdução}

Inevitavelmente, mudanças econômicas provocam impactos no ambiente construído. Com efeito, a cidade de Xangai, que não passava de uma vila até a ocupação estrangeira, transformou-se, no período compreendido entre a Primeira Guerra do Ópio (1839-42) e o fim da Dinastia Qing (1912), em centro do fabuloso comércio do "Extremo Oriente". Já no período republicano, a cidade se tornaria o modelo de desenvolvimento industrial assumido pela Nova China, com a adoção do planejamento central e a explícita associação entre a organização das necessidades imediatas da produção e a organização espacial. Se, nesse momento de nascimento e formação da República, as possibilidades de ação sobre o espaço urbano estavam exclusivamente voltadas ao desenvolvimento da função industrial, após a "abertura econômica” dos anos Deng Xiaoping (1978-92) o planejamento urbano tout court vai assumir importância crescente. Cabe ressaltar que, entre as cidades chinesas, as que sairiam à frente do processo de desenvolvimento, e também dos experimentos em planejamento urbano, foram aquelas da região do delta do rio das Pérolas, enquanto Xangai enfrentaria cerca de dez anos de perda de importância relativa no contexto nacional, o que só viria a mudar no início da década de 1990, com a ascensão de Jiang Zemin à chefia do governo central. Nesse contexto, o município

1 A pesquisa que resultou neste artigo contou com o apoio financeiro da Fapesp e com o suporte institucional do Department of Real Estate and Construction da Universidade de Hong Kong. 
começa a ganhar autonomia administrativa, e uma série de políticas liberalizantes permite ao governo local atrair investimentos estrangeiros, a exemplo do que ocorria em cidades grandes ao redor do mundo. O modelo de planejamento urbano assumido então permitiu ao Estado, a um só tempo, atuar como reformador das instituições socialistas e também como operador e financiador do desenvolvimento (Zhang, 2003), afiançando à China um novo status entre as potências mundiais.

Optou-se, neste artigo, por não introduzir o tema do conflito gerado pela modernização. No entanto, entende-se que novas formas do planejamento urbano, inspiradas por técnicas e conceitos originados no e do planejamento empresarial - sobretudo, o chamado planejamento urbano estratégico -, ao submeter a cidade aos interesses da nova estrutura de negócios, reproduzem no plano urbano um ambiente de instabilidade, acirrando o conflito na disputa pelo espaço. Obviamente, os perdedores nessa disputa são o lado mais frágil da estrutura social. Na China contemporânea o processo ganha novas nuances: ${ }^{2}$ os vencedores compõem o grupo das novas elites empreendedoras, aqueles com renda e capacidade de adaptação às novas opções de vida disponíveis, ao passo que os perdedores são aqueles arruinados pelo chai, ${ }^{3}$ ou os recém-chegados à cidade, o migrante desembaraçado da regulamentação residencial. Sem espaço para a dúvida, a renovação das cidades chinesas é um processo intenso e violento e, como ocorre alhures, a modernização mostra a sua face perversa nos processos de disciplinamento para novos usos. Esse assunto merece um tratamento à parte e não faltam ofertas na literatura acadêmica.

Neste texto, pretende-se explorar as transformações espaciais da cidade de Xangai nas últimas décadas. Ressalta-se que o texto segue uma forma mais descritiva que analítica, sem, contudo, perder de vista o caráter explicativo e processual de tais transformações. Assim, veremos que o modelo de planejamento recente ado-

2 Outra nota se faz necessária: ainda que novas formas de pensar as cidades sejam compartilhadas em diferentes lugares ao redor do mundo, entendemos que comparações a respeito do modo como as ideias são efetivadas entre cidades chinesas e não chinesas não possuem grande poder explicativo, por se tratarem de experiências muito distintas. Por exemplo, a estrutura estatal da China, que em primeira e última instância é o que define os processos de planejamento, a despeito de toda a flexibilização dos últimos anos, não parece guardar similaridade com a de nenhum Estado latino-americano. As políticas públicas, de modo geral, e de infraestrutura, em particular, seguem lá uma lógica diferente daquela do ciclo da política pública que conhecemos. Elas são estruturadas em uma hierarquia clara e rígida, desde planos nacionais amplos até medidas de implementação específicas para determinados setores e cuja agenda é definida em ciclos contínuos de cinco anos, em plenária do Comitê Central do Partido. Ali, determinam-se as principais áreas temáticas a serem abordadas na década seguinte, as quais são tornadas públicas nas Recomendações dos Planos Quinquenais. Para maiores informações, sugere-se a leitura de China, Process of the Planning Process of China. 2013, disponível em: http://planningcommission.gov.in/reports/genrep/rep_china1706.pdf. Acesso em: 22 set. 2019.

3 Chai (拆) é o sinistro sinal de "demolição” afixado nas fachadas das vilas que passarão pelo processo de substituição violenta dos usos do solo. 
tado pela China reafirma a importância da megacidade, tanto no contexto regional como no internacional. Será dada ênfase ao fato de que a política de abertura da década de 1980 e a crescente demanda do governo local por autonomia são processos que se juntaram às discussões sobre a regulamentação de um mercado de terras e no uso do leasing 4 como importante fonte de receita. Esses processos atuaram em conjunto para promover o relaxamento do controle dos usos do solo e impactaram o ordenamento urbano, estimulando o espraiamento da cidade, o remodelamento e a reocupação das áreas centrais para negócios, bem como o deslocamento e a formação de novas centralidades. Por conta desse processo, a estrutura espacial de Xangai sofreu profunda transformação. Vejamos como isso aconteceu.

\section{Breve histórico do desenvolvimento da cidade de Xangai}

Maior aglomeração urbana da China, Xangai está localizada na costa central do país, no delta do rio Yangtzé, tendo, a leste, saída para o oceano Pacífico, através do mar da China Oriental, e, ao sul, a baía do rio Hangzhou. Essa privilegiada posição geográfica facilitou o desenvolvimento dos transportes na região, inicialmente marítimos e fluviais, depois uma enorme rede de ferrovias, estradas e aeroportos. Já em meados do século XIX, a cidade adquire importância relativa na região e se transforma em centro financeiro do Oriente e, a partir de então, experimenta mudanças profundas em sua constituição, em termos tanto de sua composição física e populacional como de participação econômica no país e no cenário internacional.

Para fins analíticos, o desenvolvimento da aglomeração pode ser dividido em três fases: da formação da vila à ocupação estrangeira, o período republicano e a fase contemporânea, marcada pela abertura econômica. Neste artigo, vamos apenas citar a primeira, abordaremos brevemente o período republicano e nos deteremos com mais vagar dos desdobramentos da abertura econômica, enfatizando, em todos os casos, os processos socioeconômicos que incidiram e interferiram no processo de configuração do espaço urbano.

Embora a área urbana apresente evidências de ocupação desde pelo menos o século VII, a vila mercante foi estabelecida somente sob a Dinastia Song, em 991 d.C. No século XVI de nossa era, já no meio da Dinastia Ming, a cidade se torna conhe-

\footnotetext{
4 O leasing é um sistema de arrendamento que envolve a venda antecipada do direito de ocupação, por prazo determinado. Até 1982, a terra era posse coletiva ou do Estado e toda forma de transferência era proibida por lei. Em 1987, o sistema de arrendamento foi introduzido de forma experimental em Shenzhen e, no ano seguinte, foi normatizado em emenda à Constituição, mantendo-se, no entanto, a posse pública da terra. Somente a partir de 1990 é que o Conselho de Estado afirma o leasing como uma política pública, quando Xangai e Pequim adotam a prática (1992), que começa então a se generalizar. Para essa discussão, cf. PETERSON, 2006.
} 
cida nacionalmente pela produção de tecido de algodão. Ainda no final daquele século, contando com cerca de 200 mil habitantes, o governo imperial ali estabelece uma alfândega e Xangai ganha importância no contexto nacional (Zhu e Qian, 2003:2-5). Desse momento até tornar-se oficialmente um município, em 1927, a área ocupada era restrita ao espaço da "cidade antiga", no condado de Songjiang, hoje apenas um distrito da aglomeração de Xangai, como destacado na Figura 1, abaixo.

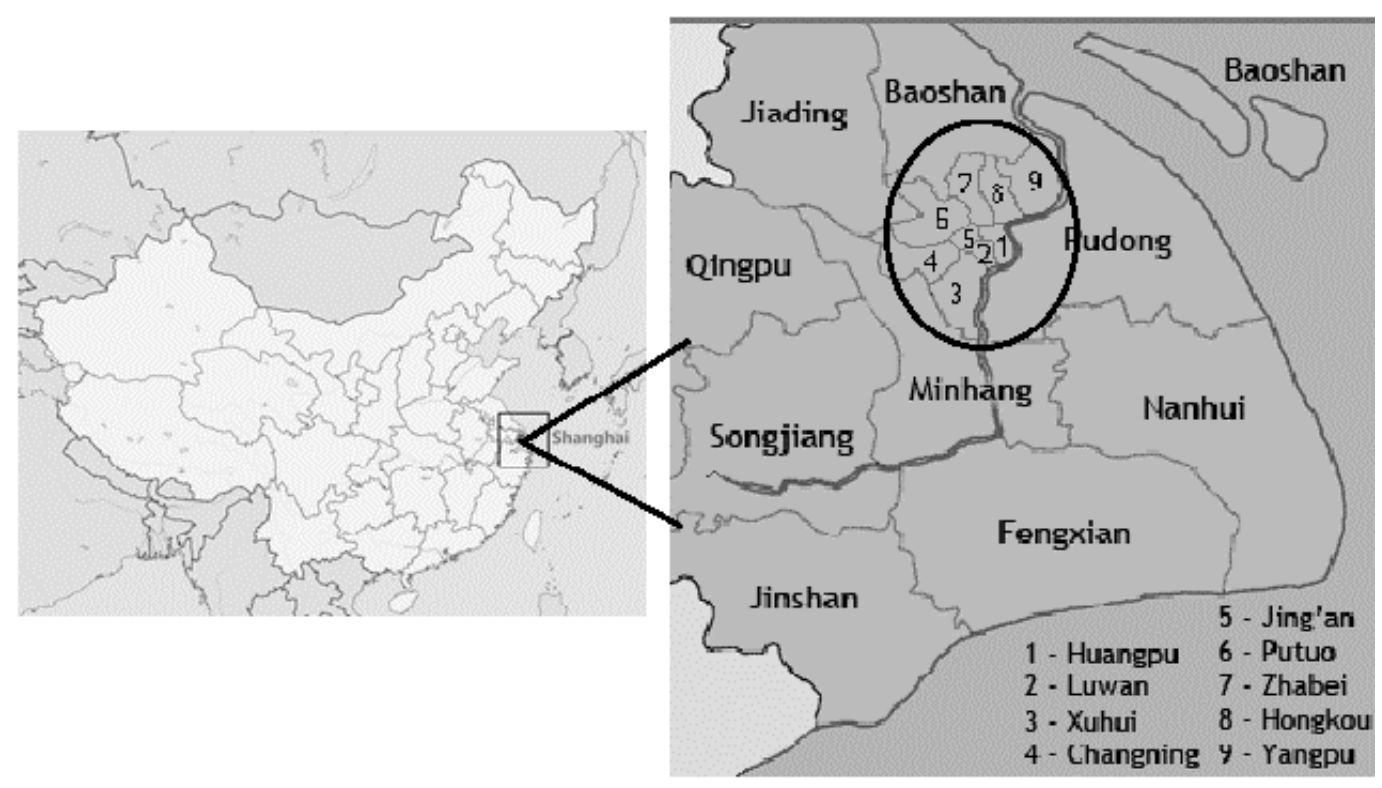

Figura 1 - Localização de Xangai e distritos, com destaque para o Condado de Songjiang, e distritos do Puxi

Fonte: Elaborado pela autora.

Durante a Dinastia Qing, ${ }^{5}$ em virtude de sua posição estratégica e do exercício de controle aduaneiro sobre as transações comerciais em toda a região, Xangai se tornou um importante porto marítimo, ligando a região do delta do Yangtzé aos demais portos da Ásia (Zhu e Qian, 2003:2-12). Sua importância cresce no século XIX, durante a Primeira Guerra do Ópio, com a ocupação da cidade pelas Forças britânicas e a imposta abertura dos portos para o comércio exterior. Até então, a cidade não passava de um pequeno aglomerado de habitações que mal havia saído dos limites do antigo muro e começava, timidamente, a se espalhar ao longo

5 Manchu foi a última dinastia imperial da China (do século XVII ao início do século XX), marcada pela abdicação do imperador Pu-Yi e a constituição da República Chinesa. Durante essa era, foi formada a base territorial do Estado chinês, com a anexação da Manchúria, da Mongólia Interior, da Mongólia, de Xinjiang e do Tibete, além dos Estados Tributários e das regiões administrativas. 

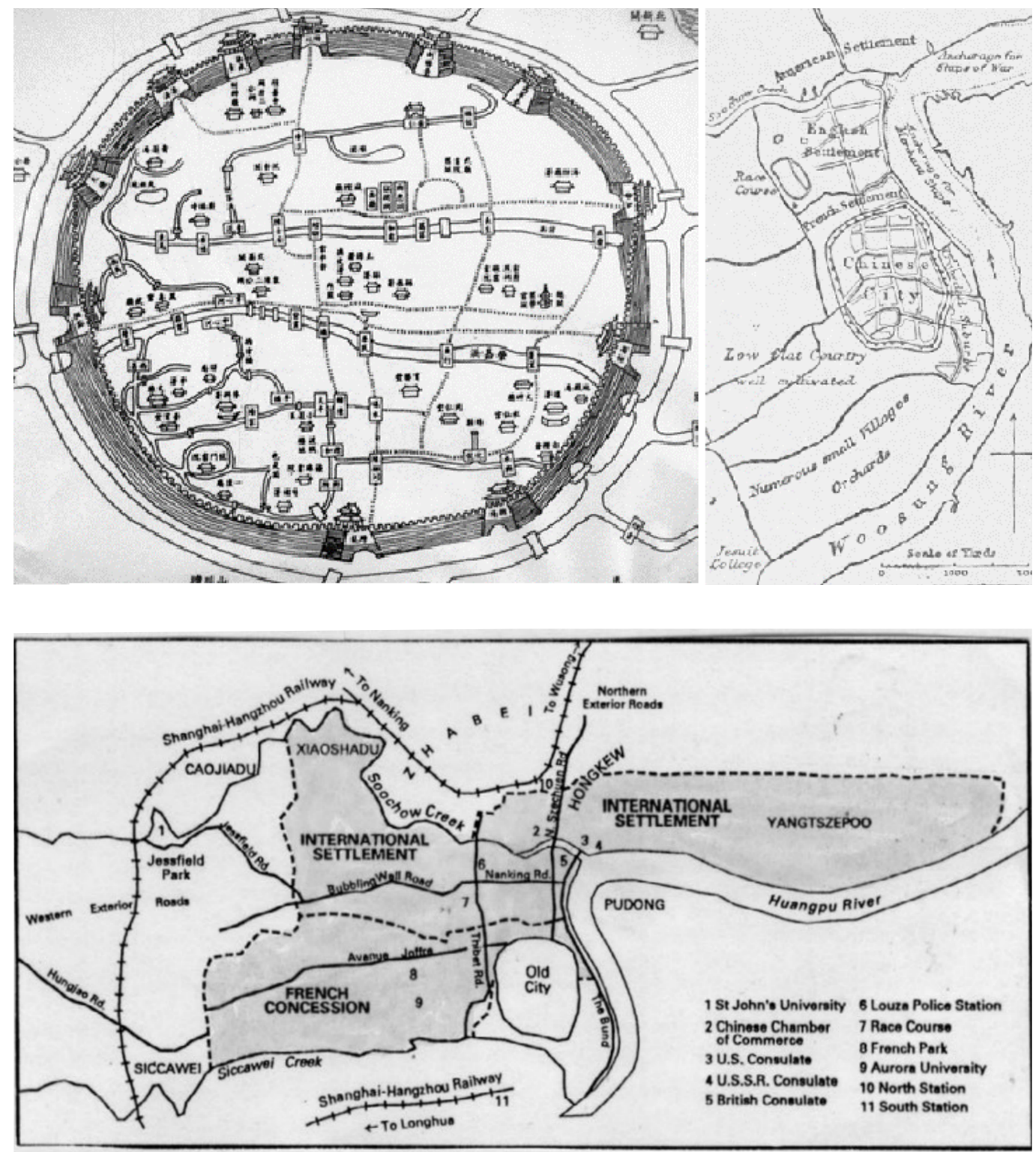

Figura 2 - Mapa da Cidade de Xangai, respectivamente no início e no fim do século XIX. Embaixo, Xangai em 1920, com os limites das duas concessões estrangeiras

Fonte: Sha et al (2014: 10) e http://www.virtualshanghai.net/Maps/Base.

do cais do rio Huangpu. Como referência, em termos de escala, hoje o município possui $6.377 \mathrm{~km}^{2}$ de área total, enquanto o assentamento inicial, Lao Cheng Xiang, possui cerca de $2 \mathrm{~km}^{2}$.

Os tratados que se seguiram à vitória inglesa, preponderantemente o Tratado de Nanjing (1842), forçaram o comércio internacional e a cessão, aos estrangeiros, das áreas exteriores à cidade murada. A invasão marca o início da urbanização moderna em Xangai, cujo crescimento físico foi determinado pela expansão dessas 
áreas de concessão (Figura 2), que "engoliram" a cidade original, formando o que é, hoje, a maior parte do centro antigo. O Huang Pu, coração da cidade, está localizado entre a área do Bund (leste), a rua Nanjing (norte), o Templo da Cidade Velha e a rua Huauhai (sul), acompanhando a margem do rio Huangpu.

Após a Primeira Guerra do Ópio e por anos seguidos, a resistência chinesa tentou retomar o controle do território de Xangai das mãos estrangeiras. Em 1863, à exceção dos franceses, reclusos na área da “Concessão Francesa”, os estrangeiros espalhados entre as demais e diversas concessões, a norte e a oeste da cidade antiga, juntaram-se, formando o "Assentamento Internacional de Xangai”. A partir de então, ao norte da velha cidade e ao longo do rio, a cidade assume contornos modernos, com as áreas ocupadas por estrangeiros segregadas das áreas chinesas. A separação étnica conformou um padrão estrutural de cidades gêmeas, com ordenamento e dinâmicas de usos distintos. Por outro lado, como ocorre com outras grandes cidades chinesas, cada bairro desenvolveu-se a partir de seu próprio núcleo, apresentando, portanto, uma lógica de ordenamento endógena. Foi nesse momento, já em meados do século XIX, que se deu a integração de Xangai ao mercado internacional ( $\mathrm{Lu}, 1999)$, quando a vila de pescadores é transformada na "Paris do Oriente”, o paraíso dos aventureiros, reclamado pelo diplomata G. E. Miller. Paulatinamente, a expansão incorpora toda a área do Puxi, cuja extensão de $288 \mathrm{~km}^{2}$ abrange sete distritos (Figura 1), nomeadamente Huang Pu, Xu Hui, Chang Ning, Jin Gan, Pu Tuo, Hong Kou e Yang Pu. Ainda hoje essa área concentra, além das atividades culturais e dos serviços e equipamentos da administração pública, cerca de 48\% dos moradores da cidade. A importância de Xangai reforça-se com a formação da Nova China Republicana, quando a produção industrial da cidade respondia por metade do valor total da produção doméstica e ela concentrava 90\% dos bancos e mais de metade do comércio exterior chinês (Yusuf e Wu, 2002).

$\mathrm{Na}$ área ocupada até o período revolucionário, a mistura das funções caracterizava o uso do espaço. Em virtude da ocupação estrangeira, o planejamento era inexistente, uma vez que as diferentes áreas apresentavam controle independente, de acordo com a jurisdição estrangeira a que cada uma pertencia. Essa situação levou a um ordenamento espontâneo e aleatório de residências e fábricas, sem deixar espaço para a expansão futura. Desde os anos iniciais da Nova China até o terceiro quartel do século XX, por conta das políticas maoístas que visavam tornar o país autossuficiente, a confusão de usos se manteve por toda a aglomeração. De acordo com Wu (2005:11), ainda em 1990, cerca de 79\% das fábricas estavam localizadas no Puxi, enquanto o restante ficava na área imediatamente contínua, sem espaçamento.

De modo geral, as cidades industriais chinesas construídas a partir de meados do século XX eram bastante similares. Juntos, o planejamento centralizado, o 
$h u k o u^{6}$ e o sistema de distribuição de empregos foram as forças que moldaram as cidades. Entretanto, até fins da década de 1960, essas forças tiveram pouca influência na formação da estrutura urbana de Xangai, dado o seu pouco significativo crescimento físico, a despeito do aumento da produção industrial e populacional. Em 1900, a cidade apresentava população de cerca de 1 milhão de residentes, 2 milhões em 1915 e 3 milhões em 1930 (Lu, 1999); em 1936, já era a sétima maior do mundo. Vinte anos depois, Xangai já apresentava mais de 6 milhões de habitantes e manteve altas taxas de crescimento populacional desde o início das contagens censitárias. Dos dados disponíveis, observam-se saltos significativos após o período de abertura e das reformas econômicas. Como se pode observar na Tabela 1, o censo de 2010 acusou uma população total de 23,1 milhões de habitantes na sua área administrativa, um crescimento de 37,5\% desde o censo de 2000 . Nesse mesmo período, a região do delta do rio Yangtzé, cujas principais cidades são Xangai, Nanjing, Hangzhou, Suzhou, Ningbo e Wuxi, estimava uma população de 90 milhões de habitantes, apenas na área urbana. Destes, cerca de 10 milhões habitavam e trabalhavam nos limites da aglomeração, sem possuir o hukou (Zheng e Bohong, 2012). No ano de 2000, o número de não registrados era de 3 milhões, o que aponta um aumento de mais de 60\% no número de migrantes sem acesso aos mesmos privilégios que os antigos habitantes. Por conta do crescimento verificado nas décadas anteriores, o ano de 2010 marcou um momento de maior rigidez no controle do registro populacional, o que explica, portanto, a brusca queda no número de habitantes.

\begin{tabular}{c|c|c} 
ano & população & porcentagem (\%) \\
\hline $\mathbf{1 9 5 3}$ & 6.204 .400 & - \\
\hline $\mathbf{1 9 6 4}$ & 10.816 .500 & $+74,3 \%$ \\
\hline $\mathbf{1 9 8 2}$ & 11.859 .700 & $+9,6 \%$ \\
\hline $\mathbf{1 9 9 0}$ & 13.341 .900 & $+12,5 \%$ \\
\hline $\mathbf{2 0 0 0}$ & 16.407 .700 & $+23,0 \%$ \\
\hline $\mathbf{2 0 1 0}$ & 23.019 .200 & $+40,3 \%$ \\
\hline $\mathbf{2 0 1 2}$ & 23.710 .000 & $+3,0 \%$ \\
\hline $\mathbf{2 0 1 4}$ & 24.151 .500 & $+1,9 \%$ \\
\hline
\end{tabular}

\author{
Tabela 1 - \\ Evolução populacional \\ Fonte: Elaboração própria sobre \\ base pública do Xangai Bureau \\ of Statístics, Statistics on National \\ Population Census.
}

6 Hukou é o sistema de registro utilizado pela República Popular da China para identificar o indivíduo e a família associados a uma área de residência. Registros parecidos são encontrados nos países vizinhos marcados historicamente pela presença da China, como o Japão, o Vietnã e as Coreias. Na China, o sistema é alvo de críticas e, desde 2014, o Conselho de Estado vem flexibilizando a sua rigidez nas pequenas cidades e áreas especiais. 
Acompanhando o ritmo do crescimento populacional, até a Revolução Cultural a expansão urbana foi preponderantemente horizontal, com a construção dos distritos fabris abertos nas franjas da cidade existente, onde a ocupação era rarefeita. Ali foram planejadas áreas de ocupação completamente independentes umas das outras, com emprego e necessidades básicas supridos pelas unidades de trabalho.7 Ainda que essas áreas incluíssem estruturas urbanas e comunitárias, como creches, escolas e hospitais, "esses distritos fabris não poderiam ser considerados áreas urbanas - eram apenas grandes lotes (large plots) de fábricas ladeados por alojamentos para os trabalhadores” (Sha, 2014:10) -, garantidas pelas unidades de trabalho, de propriedade do Estado.

Do ponto de vista das decisões estratégicas, nos anos que se seguiram ao período revolucionário, a China fecharia as portas para o Ocidente e, a partir de 1949, com o reforço da política industrial maoísta, a cidade de Xangai perde a importância como centro financeiro. No intuito de tornar o país autossuficiente, o planejamento central volta-se para a produção industrial e o Estado passa a controlar a receita da produção. De 1949 a 1983, Xangai envia cerca de $87 \%$ da sua receita total, equivalente a um sexto da receita nacional, ao governo central (Li e Wu, 2006:251). Com essa drenagem de recursos, o município se vê impedido de renovar suas infraestruturas industriais e urbanas, o que provoca a diminuição do ritmo de crescimento econômico e um revés na dinâmica urbana.

A cidade, porém, não perderia a centralidade simbólica. Em 1972, ainda em plena Revolução Cultural, Xangai foi palco do histórico encontro entre o ministro Zhou Enlai e o presidente Richard Nixon, dos Estados Unidos, cujo resultado, o Shanghai Communiqué, ${ }^{8}$ permitiu a normalização das relações entre os dois países e impulsionou a posterior abertura política e econômica chinesa durante os anos Deng Xiaoping.

No período de abertura da economia, no entanto, a escolha pelo desenvolvimento de áreas estratégicas recai sobre as cidades do delta do rio das Pérolas, que passam por transformações profundas e rápidas e se tornam o motor da economia chinesa. Na Província do Cantão, as cidades de Shenzhen e Guangzhou, vizi-

7 Danwai eram as “unidades de trabalho” da República Popular da China, na fase em que a economia era fortemente estatista e socialista. Não raro, a ligação entre o trabalhador e a sua unidade de trabalho era permanente. Com a entrada da China na economia de mercado, essa ligação tendeu a um enfraquecimento.

8 Disponível em: https://history.state.gov/historicaldocuments/frus1969-76v17/d203. Acesso em: 15 nov. 2018. Documento diplomático assinado em 28 de fevereiro de 1972, embora demorassem ainda vinte anos para que o conceito de economia de mercado socialista fosse aprovado, no $14^{\circ}$ Congresso do Partido. 
nhas das possessões inglesa e portuguesa de Hong Kong ${ }^{9}$ e Macau, passam a ser área-teste para a aplicação das reformas que viriam a reposicionar a China no mapa das grandes potências. Assim, durante a primeira onda de desenvolvimento econômico dos anos pós-Mao, essa estratégia nacional de desenvolvimento praticamente ignorou Xangai, que, em decorrência do relativo declínio econômico, viu sua estrutura física declinar.

O período de reconstrução, que se inicia com a abertura política chinesa, a partir da década de 1980, coincide com a aceleração do processo de urbanização, que só iria se completar na primeira década do século XXI (Qin e Zhang, 2014). Contudo, as decisões políticas do governo Deng Xiaoping tornaram-se insuficientes para garantir a continuidade do crescimento e do desenvolvimento quando, depois do início da década de 1990, radicaliza-se o processo de abertura. Nesse período, uma das marcas da mudança econômica de Xangai foi a reforma das empresas públicas e a permissão de operação, no território, de empresas privadas. Se, durante a década de 1980, o emprego ainda era garantido pelas danwei, mormente ligadas à produção industrial, a partir da década seguinte, o serviço público industrial sofre retração. Entre 1990 e 2000, só em Xangai, a proporção de empresas privadas aumenta de 1,5\% para quase $20 \%$ (Liu, 2001), com a contribuição das estatais diminuindo significativamente em termos de oferta de emprego. Por outro lado, naquele mesmo momento, o setor terciário começou a se fortalecer e hoje, em Xangai, já ultrapassa os setores industriais no que se refere à participação no PIB. Naquela mesma década, enquanto a contribuição do terciário subia de 31,51\% para 50,63\%, no setor de transformação ela caía de 58,38\% para 42,99\% (Li e Wu, 2006:256). Essa transição estrutural transforma a cidade, o trabalhador e o ambiente construído. Xangai se torna uma metrópole de serviços, a despeito de seu passado industrial.

Em face do peculiar caráter da questão fundiária na China, por muito tempo os processos econômicos com impacto direto sobre a estruturação das cidades foram conduzidos por políticas do governo central. Entre o fim da década de 1970 e o início da década de 1990, período da abertura econômica, o afrouxamento do controle do registro de residentes e a regulamentação econômica, entre outras, tiveram impactos essenciais sobre a ocupação e o uso da terra urbana, por toda a China continental. Senão, vejamos: as políticas de desenvolvimento chinesas buscaram elevar o crescimento da economia perseguindo uma estratégia de comércio baseada nas exportações e na atração de capital internacional. Ante a necessidade de mão de obra, tornou-se necessário acelerar a mobilidade do trabalho, flexibilizan- 
do o hukou e permitindo a migração condicional campo-cidade. Por outro lado, empresas estrangeiras foram autorizadas a operar em áreas específicas do território, atraindo capital internacional e possibilitando o surgimento de setores não estatais. Como resultado dessa paulatina abertura econômica, ainda que regulada pelo governo central, o impacto mais visível sobre as cidades foi a dinamização imobiliária, com a criação de um "mercado de terras" peculiar, dado mediante a comercialização de permissões de uso. Esse novo contexto de interação entre a abertura para a economia de mercado e as políticas de Estado mostrou-se fundamental para a reorganização do espaço urbano. De um lado, fomentou a interação entre governos provinciais e locais e, de outro, os municípios assumiram um nível de autonomia nunca antes experimentado. Vejamos como esse processo se concretizou e como reconfigurou o espaço da aglomeração da grande Xangai.

\section{A formidável transformação de Xangai nos anos 1990, no contexto da abertura e da ascensão nacional de Jiang Zemin}

Nos anos Deng Xiaoping, por conta do interesse do governo central de estimular o desenvolvimento da fronteira sul, a região do delta do rio das Pérolas se transforma no motor da economia chinesa, assumindo precedência na aplicação de recursos, no lugar antes ocupado por Xangai. A esse processo se somava outro, geral e anterior, no qual a indústria absorvia o investimento, deixando pouco para a manutenção e a melhoria urbanas. Em tais condições, Xangai vê sua estrutura física entrar em uma fase de rápida dilapidação (Sha et al, 2014:13) e, por essa razão, permaneceu, até a década de 1980, com a infraestrutura física herdada das primeiras décadas do século XX, com insuficiência nas redes de água, esgoto e pavimentação, além de falta de áreas de lazer e déficit habitacional (Wu e Yeh, 1999:209). Cumpre lembrar que foi durante esse período de declínio, ocasionado tanto pela falta de investimentos como pelas migrações, que a área histórica se tornou extremamente densa, com o aumento do número de habitantes nos tradicionais lilongs ${ }^{10}$ (Figuras 3 e 4), dos quais poucos restam na cidade. Nessa áreas, chegou a haver 60 mil pessoas por quilômetro quadrado.

Com a ascensão dos ex-prefeitos de Xangai, Jiang Zemin e Zhu Rongji, ao governo central, ${ }^{11}$ o Estado começou a atuar como reformador das instituições socialistas

10 Lilong são blocos de antigas residências em Xangai, equivalentes aos hutong de Pequim. São estruturas arquitetônicas localizadas em ruas estreitas sobre as quais se empilham formas residenciais que refletem profundamente o passado colonial xangaiense.

11 Membro do Partido Comunista desde a década de 1940, Zemin foi prefeito de Xangai (1987-89), secretário-geral do Partido Comunista (1989-2002) e presidente da República Popular da China (1993-2003). Rongji, por sua vez, foi prefeito de Xangai (1989-91) e vice-presidente de Jiang Zemin (1998-2003). 

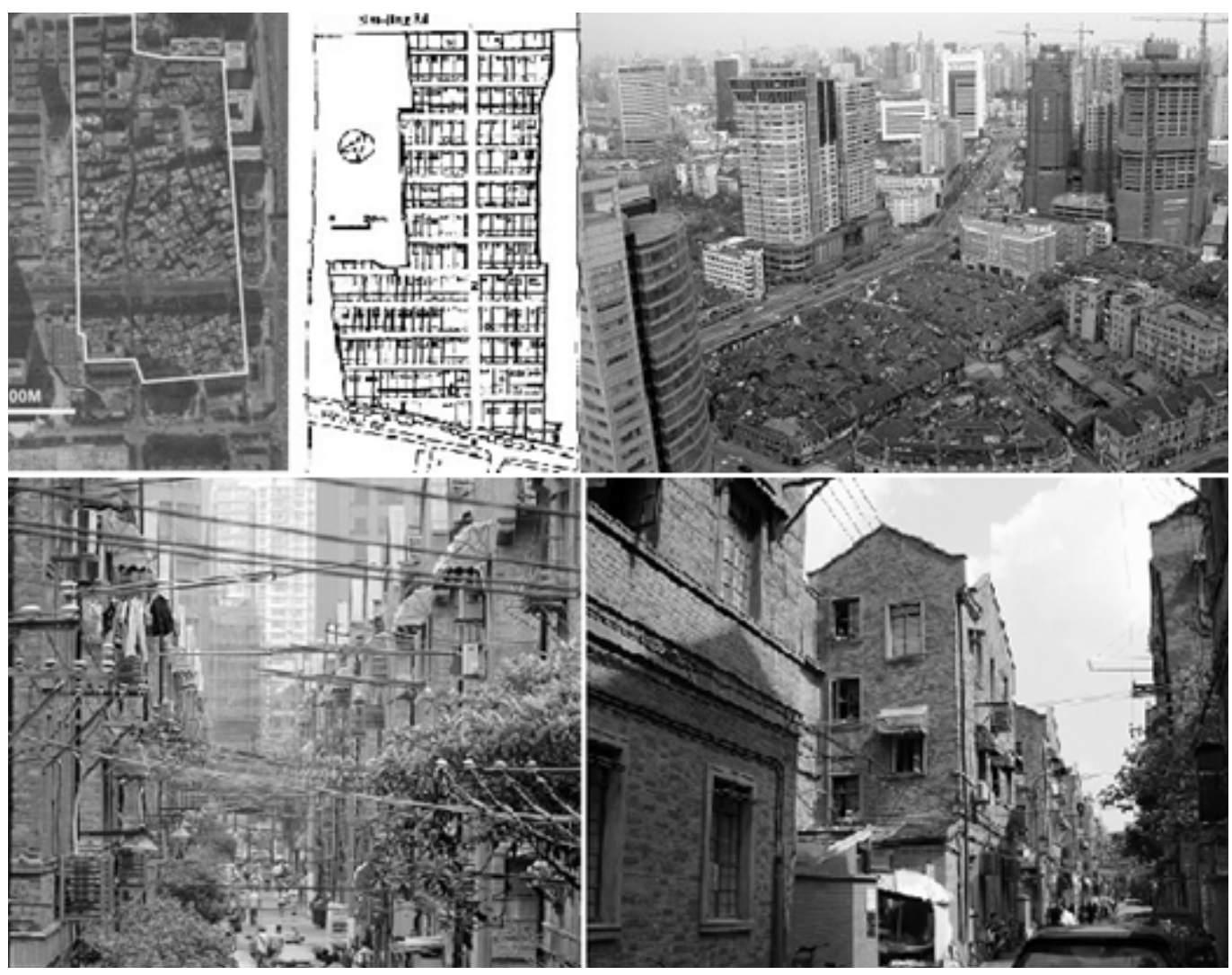

Figura 3 - Lilong Jiang-na (ou Jing'an), no centro de Xangai, construído em 1932

Fonte: Banco de imagens do prof. Wong Wai Man, da City University of Hong Kong, e da autora.

e também como desenvolvedor e financiador das políticas de planejamento. A mudança de estratégia implicava igualmente a modificação na alocação dos impostos, antes revertidos apenas para o governo central. Como resultado, o governo local adquire autonomia nas suas decisões quanto à alocação de recursos, ao passo que o governo central se liberta dos planos de distribuição da produção, passando a assumir uma função macroeconômica de planejamento.

Outro fator importante desse novo direcionamento se liga à reforma habitacional de 1990 e à implementação de leasing nos negócios imobiliários, responsáveis por converter o sistema socialista de provisão de habitação em um mercado de terras, inclusive com a possibilidade da aquisição imobiliária por estrangeiros. O governo local utilizou essas novas ferramentas de gestão para, entre outras coisas, oferecer infraestrutura, e a cidade experimenta um desenvolvimento sem precedentes. O rearranjo administrativo e financeiro permitiu impulsionar o desenvolvimento por meio do aumento das inversões diretas do governo central, com linhas especiais de empréstimos em bancos públicos, ofertas diretas de recursos financeiros (Yusuf e Wu, 2002) e vantagens especiais para investimento em infraestrutura. 


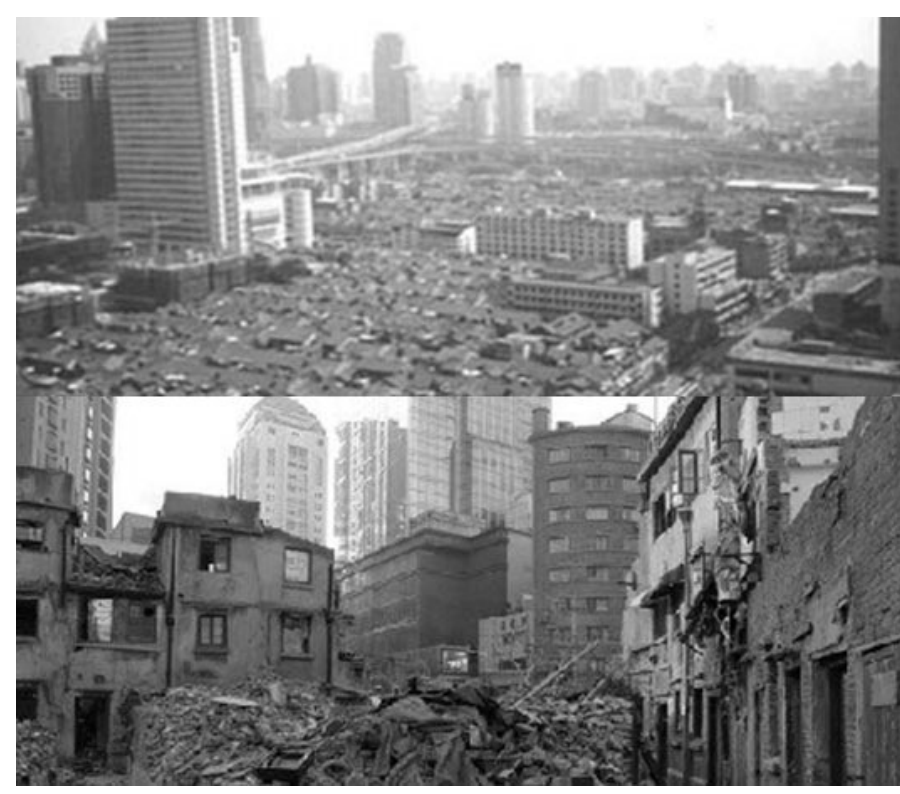

Figura 4 - Destruição de um lilong nas décadas de $1990 \mathrm{e}$ 2000, respectivamente Fonte: Prof. Wong Wai Man, da City University of Hong Kong.

Entre 1991 e 1996, cerca de US 10 bilhões foram investidos em pontes, túneis anéis viários interno e externo, vias elevadas e na extensão e na criação de linhas de metrô (Wu, 1999:66).

As políticas e os recursos preferenciais canalizados para Xangai foram singulares. À cidade foi concedido o direito de abrir localizações específicas para o terciário visando à captura do investimento estrangeiro. Permitiu-se a entrada de joint ventures sino-estrangeiras, estabeleceu-se a Bolsa de Xangai, legalizou-se a transferência dos direitos de utilização de terrenos pertencentes ao Estado para a produção imobiliária privada, etc. O governo municipal atua diretamente na produção imobiliária, por meio de empresas e bancos estatais.

Com a mudança de estratégia econômica e a retomada de Xangai como a mais importante cidade do país, uma fase de descentralização da estrutura urbana se inicia. Áreas residenciais são construídas fora dos limites anteriores - no centro expandido, nas áreas suburbanas, nas áreas rurais e também se derramam em direção aos limites das cidades adjacentes - enquanto o centro passa por um processo de reconstrução absolutamente formidável na história das cidades. A acelerada realocação industrial das últimas duas décadas gera impactos visíveis no neófito mercado residencial. Espaços antes ocupados por plantas produtivas são disponibilizados para o mercado imobiliário ao longo do tecido, criando uma nova onda de reformas que removeu as barreiras ao desenvolvimento desse setor de negócios (Wei e Leung, 2005:20-21; Zhang, 2003).

As áreas residenciais mais dilapidadas do centro da cidade, como o lilong (Figuras 3, 4 e 5), são as que apresentam as maiores densidades. Ali, a resistência à 


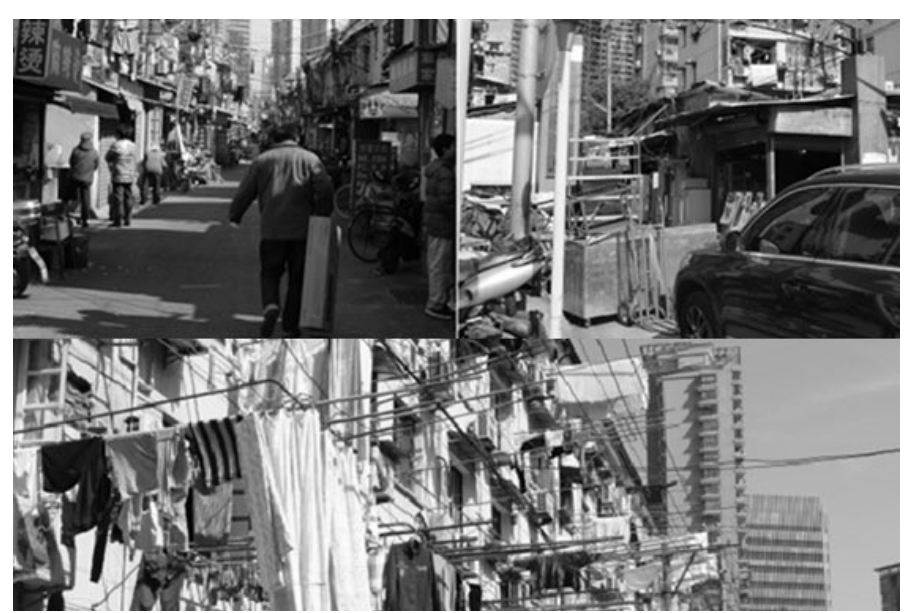

Figura 5 - Dentro do lilong e na área em transição, no entorno do Bund Fontes: Acervo da autora.

mudança e a resiliência dos antigos moradores dificultaram a entrada do mercado imobiliário, por conta dos altos custos associados às realocações. Desse processo resulta uma justaposição de edifícios comerciais high-tech e antigas e deterioradas edificações residenciais que datam do final da última dinastia (Wu, 2006). Uma vez instalado o mercado de terras e com a economia chinesa exigindo novos espaços de produção e serviços, essas últimas permanências do antigo, paulatinamente, desaparecem da paisagem. Ainda assim, as antigas áreas residenciais densamente ocupadas, com infraestrutura inadequada e uso misto do solo, desafiam o Estado em seu intuito de construir uma nova China, principalmente em se tratando de questões relativas à segurança habitacional dos moradores.

Para a reconstrução dessas áreas residenciais, o Estado realoca os residentes fora dos espaços centrais, em áreas adjacentes ou mesmo ao longo dos espaços reconfigurados. Foi somente na década de 1990 que a cidade se propôs substituir 3,6 milhões de metros quadrados de estruturas residenciais comprometidas. Isso significou mais de 60 milhões de metros quadrados de áreas construídas ou renovadas, com provisão de serviços públicos antes inexistentes ou incompletos e insuficientes, incluindo energia, água e comunicações (Wu, 2006).

É importante destacar que, antes das reformas, o provimento habitacional era garantido pelo empregador, ${ }^{12}$ financiado pelo orçamento fiscal e distribuído pelas autoridades governamentais e pelas estruturas de trabalho do Estado. Assim, é possível afirmar que as reformas possibilitaram a introdução tanto do mercado imobiliário como da comercialização das permissões de uso do solo, com limitações que foram aos poucos alargadas. Como resultado, para todo o território chinês, entre 1980 e 1990, o investimento em habitação foi responsável por cerca de 90\% do mon- 


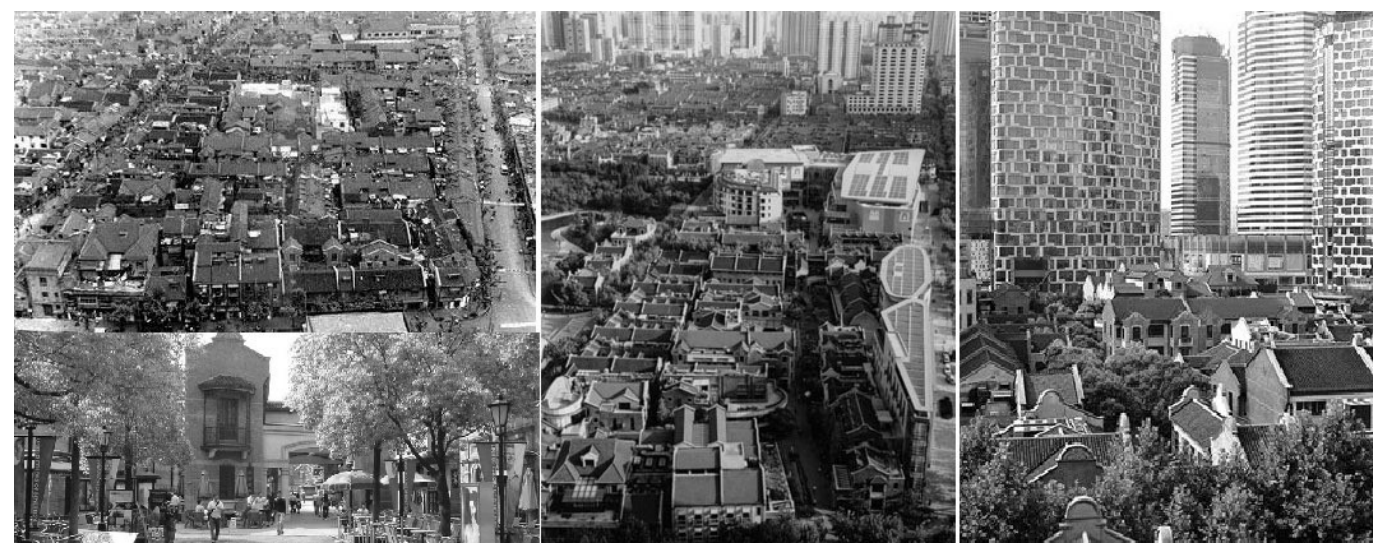

Figura 6 - Xin Tian Ti, distrito central antes e depois das reformas

Fonte: Banco de imagens do prof. Wong Wai Man, da City University of Hong Kong.

tante total investido em habitação para o período entre 1949 e 1980 (Chiu apud Wu, 1999, e Wang, 2012). Para garantir acesso habitacional aos mais carentes, criou-se um fundo nacional e público de reserva, universalizado a partir do ano 2000. Hoje, e em decorrência dessa nova orientação, a produção de habitação não está mais sob a responsabilidade exclusiva do Estado e deixou de ser bem gratuito garantido aos residentes urbanos, à luz do que já havia acontecido em outras cidades especiais, como as do delta do rio das Pérolas.

A combinação de todos esses elementos, nomeadamente a relocalização das instalações industriais, a abertura de áreas para o terciário, o reassentamento residencial, o novo e singular mercado de terras, a renovação da área do antigo centro e a suburbanização, tem mudando o padrão de usos do solo da cidade de Xangai desde o início da década de 1990. Vejamos como esses fatores foram canalizados pelas administrações públicas por meio dos planos de desenvolvimento.

\section{Planos de desenvolvimento urbano e gestão da urbanização no contexto das reformas econômicas}

Com vistas a organizar a dinâmica espacial, diversas iniciativas voltadas para o planejamento emergiram a partir de fins da década de 1980, como os Planos Diretores de 1986, 1991, 1999, o Plano da Expo 2010, bem como as políticas macroeconômicas do governo central responsáveis, em primeira instância, por todas essas mudanças. Como resultado da implementação desses planos, provocou-se a aglutinação das instalações produtivas nas áreas especiais, com a liberação de espaço, no centro, para usos mais nobres; nos interstícios restantes, por toda a região central e do centro expandido, novas centralidades continuaram a ser estimuladas. Assim, áreas anteriormente caracterizadas por alguma oferta de serviços e 
comércio ${ }^{13}$ viram esses usos serem intensificados por conta do estímulo às economias de escala.

A reorientação do desenvolvimento da cidade foi pensada já em 1986, com a constituição do Shanghai Master Plan. Nele, tentou-se equacionar os problemas urbanos tendo em conta o potencial futuro da cidade, definindo-se a expansão máxima do centro e sua ligação com as áreas adjacentes, periféricas e satélites, bem como a forma e a intensidade da conurbação. $\mathrm{O}$ equívoco mais visível desse plano foi a insistência no crescimento horizontal no lugar da ênfase no aumento das densidades nas áreas centrais. Ainda assim, a sua efetivação se tornaria essencial para o funcionamento de Xangai, principalmente porque a acomodação de gigantescas instalações industriais nos extremos norte e sul, respectivamente em Baoshan e em Jinshan, exigia um sistema de circulação mais eficiente e rápido que os disponíveis até então.

O plano de 1986 estabelecia, ainda, que as regiões de Pudong e Lujiazui seriam modernizadas e teriam seu uso voltado para funções nobres, com intensificação da circulação entre estas e o centro. Como resultado direto do plano, e aproveitando a possibilidade da aplicação de compensações financeiras, a administração local começa a promover o reajuste dos usos do solo nessas regiões, com a reconstrução das áreas deterioradas e a redistribuição tanto das ocupações residenciais como das industriais.

Como vimos, nos anos 1990 a importância de Xangai no contexto nacional havia mudado, e diante da possibilidade da inserção da China no mercado mundial, a cidade assumiria uma posição estratégica fundamental que a elevaria a centro econômico e financeiro internacional. Urgia a continuidade do processo de mudanças. Assim, para impulsionar a abertura das cidades da região do delta do Yangtzé, e de acordo com o previsto já no plano de 1986, o governo central voltou sua atenção para o desenvolvimento da região de Pudong com a elaboração do Comprehensive Plan of Pudong New District. Com as obras concebidas e iniciadas no mesmo ano, em 1991, visava-se assegurar a adequada ocupação da área estimulando o seu desenvolvimento em sentido geral, mas com vistas explícitas ao crescimento do setor financeiro, do comércio exterior e de serviços e à elevação de Xangai à categoria de cidade mundial.

Localizado na margem leste do rio Huangpu, o distrito de Pudong possui área total de $842 \mathrm{~m}^{2}$ e localização formidável, de frente para o oceano Pacífico e para o Bund, antigo distrito financeiro da cidade. Com a injeção de bilhões de yuans, em cinco anos o governo conseguiu implementar dezenas de grandes projetos de intras, todas localizadas no Puxi, no entorno do Bund, tornaram-se predominantemente comerciais, com lojas e centros de compra tomando o lugar de residências e fábricas. 

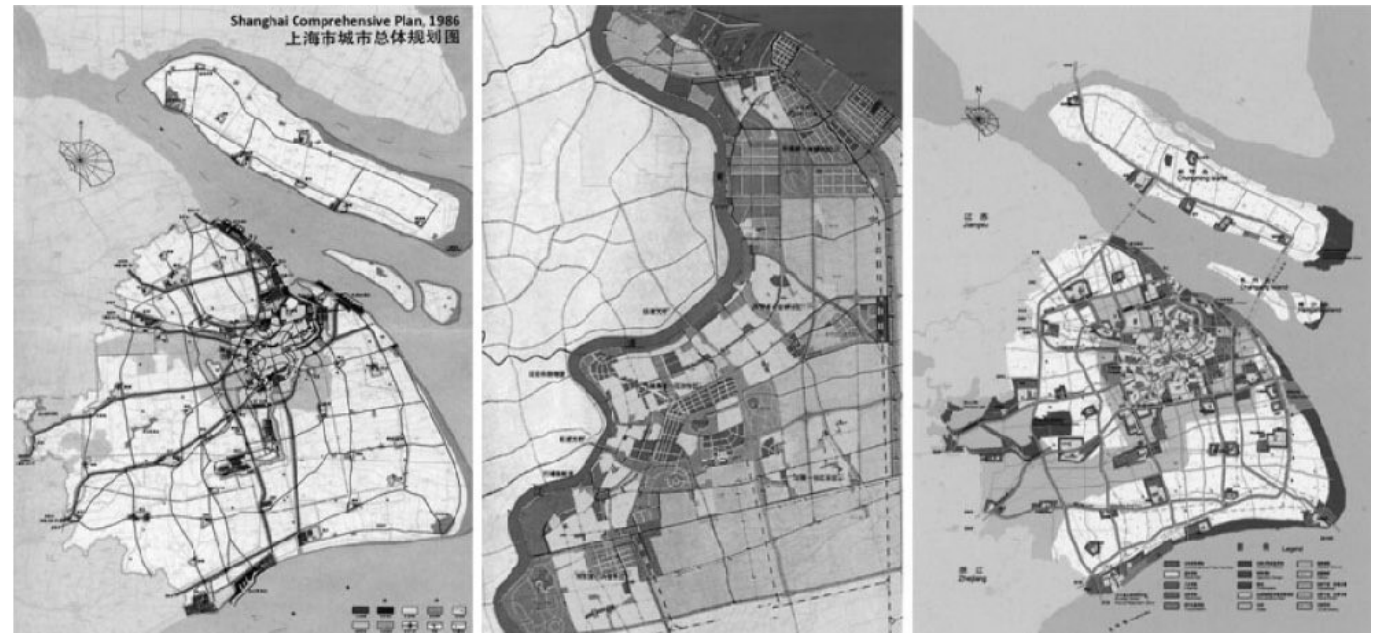

Figura 7 - Planos diretores: Shanghai Comprehensive Plan, 1986; Comprehensive Plan of Pudong New District, 1991, e Shanghai Comprehensive Plan 1999-2020, 1999 Fonte: Sha et al, 2014, p. 14.
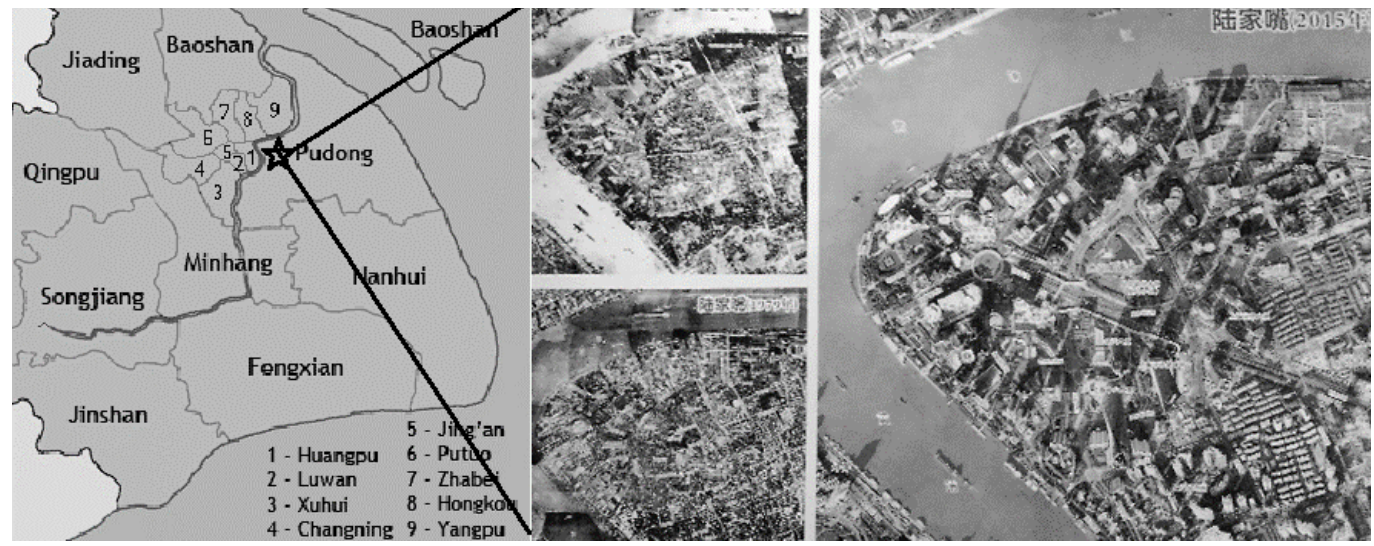

Figura 8 - Divisão administrativa de Xangai. Destaque para a área de Lujiazui, no distrito de Pudon

Fonte: Elaboração da autora sobre imagem encontrada no Centro de Planejamento Urbano de Xangai (Shanghai Urban Planning Center), em 2016.

fraestrutura, entre os quais se incluem instalação de gás encanado, tratamento de água e esgoto, a construção do porto e do aeroporto internacional de Pudong, a atualização de equipamentos de telecomunicações e a reordenação do sistema viário, com novas linhas de metrô e ligação entre trens de alta, média e baixa velocidades, além da construção de várias pontes e túneis que cruzam o rio.

O desenvolvimento da região de Pudong se destaca como exemplo de ação direta de planejamento do governo central pela conversão da região de Lujiazui em centro financeiro de importância mundial. O desenvolvimento dessa área se tornou o carro-chefe das reformas econômicas chinesas e foi parte essencial de uma 


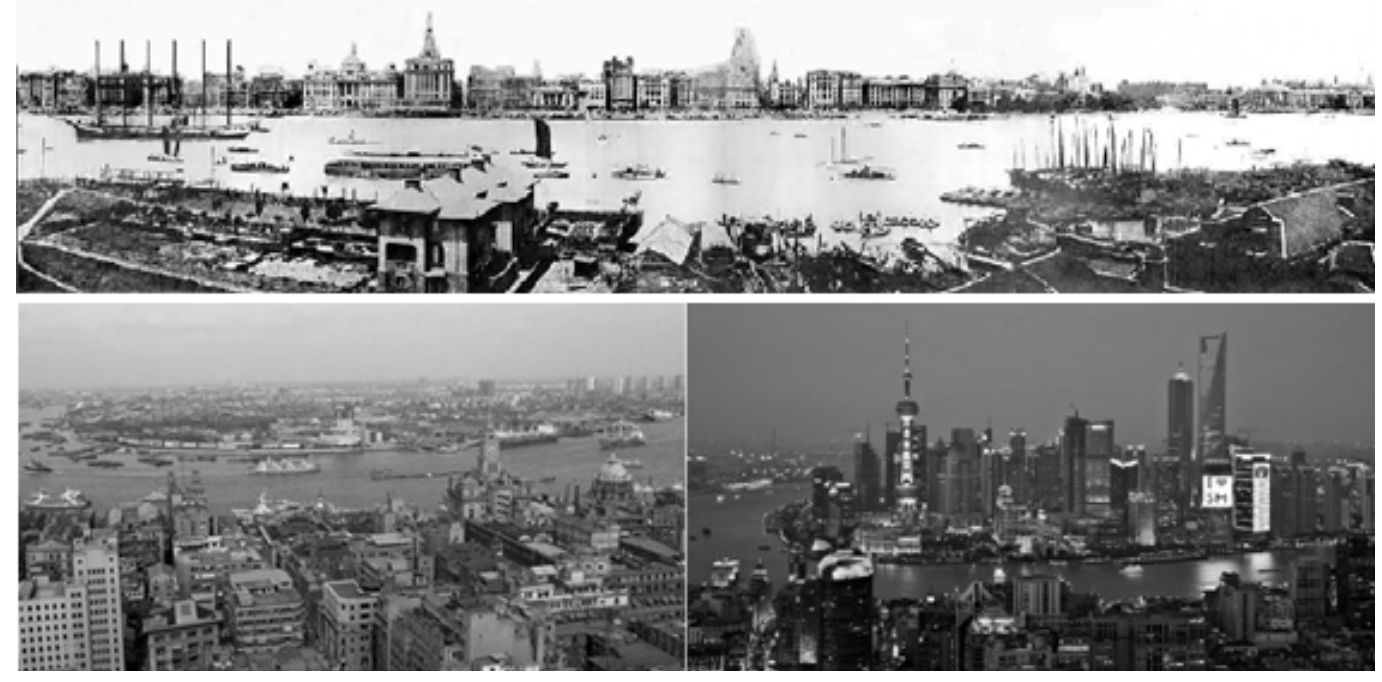

Figura 9 - Pudong visto em três tempos, em sentido anti-horário - 1930 (de Pudong para o Bund), 1990 e 2010.

Fonte: Banco de imagens do prof. Wong Wai Man, da City University of Hong Kong; montagem da autora.

estratégia de desenvolvimento nacional de grande sucesso ( $\mathrm{Li}$ e $\mathrm{Wu}, 2006: 253$ ). De 1990 a 2000, acompanhando a implementação do plano para a ocupação de Pudong, o PIB de Xangai cresceu de 75,5 bilhões de yuans para 456 bilhões, com uma taxa de crescimento médio anual de 20,8\%, quando o da China já chegava a fantásticos 8\% (Zhang, 2003; Yusuf e Wu, 2002). A cidade tornou-se atrativa para milhares de instituições financeiras, empresas e representações transnacionais, além de atrair um volume crescente de investimentos nas mais diversas áreas da produção. Com isso, Xangai viu-se em meio a um novo processo revolucionário, que transformava a forma espacial ao reformular o horizonte da cidade: arranha-céus rasgaram as áreas já adensadas, introduzindo novos espaços residenciais, comerciais e hoteleiros, além de indústrias internacionais e nacionais, que despontavam aproveitando as possibilidades de investimentos.

O reordenamento foi aprofundado nos planos diretores seguintes, principalmente no de 1999, o Shanghai Comprehensive Plan 1999-2020, responsável, em última instância, pela reconfiguração da paisagem da cidade, mas também no Shanghai Expo 2010 Master Plan. O planejamento em larga escala possibilitou a construção do centro financeiro de Lujiazui, dando a esse espaço o mesmo caráter de CBD da cidade ocidental. Em seus limites, localizam-se a maioria dos icônicos arranha-céus da cidade, assim como zonas industriais.

Em linhas gerais, os planos de 1991 e de 1999, posteriormente articulados com o Plano da Expo 2010, deram à cidade um acúmulo de conhecimentos relativos ao 
planejamento urbano, os quais, se não dirimiram os problemas, ao menos mitigaram parte significativa daqueles causados pela associação entre, de um lado, a orientação estreita do planejamento socialista e, de outro, a intensidade do processo urbano que a China, e particularmente Xangai, enfrentara nas últimas décadas.

Apresentando uma visão um tanto quanto distinta dos anteriores, o Comprehensive Plan of Shanghai 1999-2020, constitui-se em importante instrumento de orientação para o desenvolvimento da cidade, com planejamento da infraestrutura necessária para garantir e manter sua nova posição. O plano reflete a intenção de aprofundar as transformações operadas ali, com enfoque no reordenamento da relação centro-bairros e na integração do centro da cidade com os seus subúrbios e cidades-satélites, visando à eficiência das conexões. De porte de novos referenciais urbanísticos, planejou-se a urbanização dos subúrbios, levando em consideração tanto o movimento de migração para Xangai como o movimento de diminuição das densidades das áreas centrais. Por sua vez, a área correspondente ao centro velho ganhou atenção específica, com a intenção de elevar o padrão das ocupações, por intermédio de programas de conservação do patrimônio histórico, do estímulo à renovação urbana, da reutilização de espaços antigos e obsoletos por usos novos e criativos e do incentivo aos usos do terciário avançado evidenciando uma preocupação de construir a imagem de uma cidade moderna e voltada à promoção da melhoria do ambiente para o fomento de uma identidade urbana xangaiense.

\section{Conclusão}

Como principal cidade industrial chinesa, Xangai experimentou todos os movimentos e tentativas de indução do crescimento e do desenvolvimento: de vila à importante cidade comercial, no período da ocupação estrangeira; de cidade comercial proeminente do "Oriente distante" a modelo de cidade industrial da Nova China Republicana, seguida pela decadência dos anos pós-Revolução Cultural até seu ressurgimento, em grande parte, possibilitado por sua inserção às Zonas Econômicas Especiais, já em 1984. Xangai teve a permissão de iniciar as reformas econômicas de 1991 e o fez por meio de um plano estratégico baseado no desenvolvimento de Xangai-Pudong, com a deliberada conversão da região de Lujiazui em centro financeiro do país, da Ásia e do mundo. Simbolicamente, a concentração e o uso explícito da icônica arquitetura observada ali foram empregados para validar as reivindicações dos planejadores urbanos de que Xangai poderia recuperar o status de cidade global, perdido nas décadas revolucionárias.

O planejamento urbano, com a construção de novas áreas e a reconstrução de estruturas físicas deterioradas, tornou-se indispensável nesse novo contexto, ao trazer luz aos dois movimentos que dirigem a expansão da aglomeração: um de es- 
palhamento em direção às áreas suburbanas e outro no sentido de reorganização e adensamento das áreas centrais. O movimento de suburbanização vem acompanhado da criação de novos centros, previstos nos Planos Diretores de 1986 e 1991-1996, tanto nos limites da municipalidade como nas cidades adjacentes, evidenciando uma tendência à aglutinação das cidades que compõem a região do delta do Rio Yangtzé. Por seu turno, o movimento de adensamento do centro consolidado se dá, em parte, em função da valorização daquelas áreas, mas, principalmente, pela resposta do planejamento local em relação aos novos paradigmas urbanísticos e ao entendimento do novo status ocupado pela aglomeração.

Embora o processo de reconstrução de Xangai ainda não tenha sido concluído, a cidade viu seu parque edificado, preponderantemente aquele localizado no centro, ser renovado e readaptado e ao novo contexto produtivo mundial. Ao longo dos últimos anos e por tentativa e erro, o Estado chinês tem implementado as condições presumíveis de um planejamento o mais integrado possível dentro de um contexto no qual ele, o próprio Estado, é colocado na berlinda, tanto por pressões externas de abertura econômica - a saber, a desregulamentação das condições históricas nas quais se deu o desenvolvimento chinês - como por razões de ordem interna, como as exigências relativas à mudança nos níveis de reprodução da força de trabalho.

O processo de desenvolvimento econômico da China, acompanhado das mudanças verificadas no cerne de suas mais importantes cidades, a exemplo do que ocorreu com Xangai, tem criado consenso em torno da necessidade de adaptação do espaço da produção aos novos contextos que ela apresenta. Com isso, provê-se o espaço urbano das infraestruturas necessárias, em última instância, responsáveis pela dinamização da produção. A reconfiguração da cidade, particularmente com a regulação e as infraestruturas providas pelo Estado, tem sido responsável pela promoção de espaços menos heterogêneos e mais acessíveis, ainda que sofrendo uma pressão gigantesca para contemplar todos os usos que uma sociedade em processo de urbanização e desenvolvimento acelerados requer.

\section{Referências Bibliográficas}

CAMPANELLA, Thomas J. The Concrete dragon: China's Urban Revolution and What it Means for the World. New York: Chronicle Books, 2012.

HE, J. Implementation of the Shanghai Master Plan (1999-2020). In: Association of European Schools of Planning. 26th Annual Congress, Ankara, Turquia, 11-15 jul. 2012.

LI, Ling-hin. Urban Land Reform in China. Londres: Macmillan Press, 1999. 
LI, Z.; WU, F. Socioeconomic Transformations in Shanghai (1990-2000): Policy Impacts in Global-National-Local Contexts. Cities, 23(4), 250-268, 2006.

LU, H. Beyond the Neon Lights: Everyday Shanghai in the Early Twentieth Century. Berkeley: University of California Press, 1999.

MA, Bing. New Urbanism and Urban Development in Contemporary China. Tese de Doutorado. Carleton University, 2002.

PETERSON, George E. Land Leasing and Land Sale as an Infrastructure-financing Option. The World Bank, 2006.

QIN, B.; ZHANG, Y. Note on Urbanization in China: Urban Definitions and Census Data. China Economic Review, 30, 495-502, 2014.

SHA, Y.; WU, J.; JI, Y.; CHAN, S. L. T.; LIM, W. Q. Shanghai Urbanism at the Medium Scale. Berlin: Springer, 2014

SPENCE, Jonathan D. The Search for Modern China. WW Norton \& Company, 1990.

WANG, M. Y.; KEE, P.; GAO, J. Transforming Chinese Cities (v. 116). Oxon, New York: Routledge, 2014.

WANG, Yuwei. The Chinese Unit. Persistence of the Collective Urban Model in Beijing. Architectural Association Graduate School, Projectives Cities AA, 2012.

WU, F.; XU, J.; YEH, A. G. O. Urban Development in Post-reform China: State, Market, and Space. Oxon, New York: Routledge, 2006.

WU, F.; YEH, A. G. O. Urban Spatial Structure in a Transitional Economy: the Case of Guangzhou, China. Journal of the American Planning Association, 65(4), 377-394, 1999.

WU, W. City Profile: Shanghai. Cities, 16(3), 207-216, 1999.

Migrant Settlement and Spatial Transformation in Urban China: the Case of Shanghai. In: World Bank Third Urban Research Symposium, 4-6 abr. 2005.

YEARBOOK, China Statistical. National Bureau of Statistics of China. China Statistical Yearbook, 2012.

YEH, A. G. O.; WU, F. The Transformation of the Urban Planning System in China from a Centrally-Planned to Transitional Economy. Progress in Planning, 51(3), 167-252, 1999.

YUSUF, S; WU, W. Pathway to a World City: Shanghai Rising in an Era of Globalisation. Urban Studies, 39(7), 1213-1240, 2002.

ZHANG, L. Y. Economic Development in Shanghai and the Role of the State. Urban Studies, 40(8), 2003.

ZHANG, M. From Public to Private: The Newly Enacted Chinese Property Law and the Protection of Property Rights in China. Berkeley Business Law Journal, 5, 2008.

ZHENG, Z.; BOHONG, Z. Study on Spatial Structure of Yangtze River Delta Urban Agglomeration and its Effects on Urban and Rural Regions. Journal of Urban Planning and Development, 138(1), 78-89, 2012.

ZHU, L.; QIAN, Z. The Case of Shanghai, China. Global Report on Human Settlements, 2003. 


\section{Lucimara Flávio Reis}

Professora-adjunta do curso de Ciência Política e Sociologia, Universidade Federal da Integração Latino-Americana (Unila), Foz de Iguaçu/PR - Brasil.

Email: lucimara.reis@unila.edu.br

ORCID: 0000-0002-6956-5451

Submissão: 22 de novembro de 2018

Aprovação: 11 de setembro de 2019

Como citar: REIS, L. F. A aglomeração de Xangai e as transformações da estrutura espacial da sua área central: declínio e renovação. Revista brasileira de estudos urbanos e regionais. V.22, E202002, 2020.

DOI: 10.22296/2317-1529.RBEUR.202002

Artigo licenciado sob Licença Creative Commons (CC-BY) 